\title{
EDITORIAL
}

\section{Special issue on interpretation of epidemiologic studies of multipollutant ambient air exposure and health effects}

\author{
Journal of Exposure Science and Environmental Epidemiology (2007) 17, S1; doi:10.1038/sj.jes.7500622
}

The U.S. Clean Air Act requires the U.S. Environmental Protection Agency (EPA) to carry out periodic reviews of the National Ambient Air Quality Standards (NAAQS) for major "criteria" air pollutants and to revise the NAAQS for a given pollutant, as appropriate. As part of these reviews, the National Center for Environmental Assessment-Research Triangle Park Division (NCEA-RTP) within EPA's Office of Research and Development (ORD) assesses the newly available scientific information in Integrated Science Assessments (formerly known as Air Quality Criteria Documents) that provide the scientific bases for the reviews of the NAAQS for particulate matter, ozone, carbon monoxide, oxides of nitrogen, sulfur oxides, and lead.

NCEA-RTP sponsored a workshop, Interpretation of Epidemiologic Studies of Multipollutant Exposure and Health Effects, on December 13-14, 2006 in Chapel Hill, North Carolina, USA to inform the Agency's evaluation of the science in the review of the NAAQS for all criteria pollutants. The workshop addressed various issues involved in the interpretation of air pollution epidemiologic study results. These included issues related to exposure assessment, multipollutant confounding and effect modification, statistical modeling, and biological plausibility. Cross-cutting issues pertaining to the evaluation of all of the criteria air pollutants were examined, with emphasis placed on studies involving evaluation of multipollutant health risks.

This workshop was planned to advance interpretation and understanding of criteria air pollutant health effects analyses in population-level epidemiologic studies, with a focus on multipollutant exposures. The principal goals of this workshop were to (1) assess issues related to the interpretation of the epidemiologic literature, particularly related to the use of community ambient air quality monitors; (2) discuss new methodologies and approaches to advance future epidemiologic research in the areas of exposure error, confounding and effect modification by co-pollutants, and statistical modeling; and (3) evaluate the extent to which evidence from human clinical and animal toxicologic studies aids in interpretation of findings observed in the epidemiologic literature.

The workshop was organized around four sessions. They are as follows:
- Session One: Exposure Assessment and Related Errors in Epidemiologic Studies

- Session Two: Issues Involved in Interpretation of Epidemiologic Analyses - Multipollutant Exposures

- Session Three: Issues Involved in Interpretation of Epidemiologic Analyses - Statistical Modeling

- Session Four: Biological Plausibility of Health Effects due to Air Pollutants

Each session included presentations on pertinent issues related to the session topic followed by a panel discussion. This special issue of the Journal of Exposure Science and Environmental Epidemiology includes selected papers by the presenters and panel members as well as reviews of the panel discussions that took place at the workshop.

We would like to acknowledge all the presenters and panel members who made important contributions both at the workshop and to this special issue. Special thanks goes to the chairs of each session for their extraordinary efforts which included, but were not limited to, identifying and recruiting presenters, preparing topics for the panel discussion, and organizing the panel members' contributions for the panel discussion review papers. The chairs for each session were William E. Wilson (U.S. EPA) and Jeremy A. Sarnat (Emory University) for Session One; Richard T. Burnett (Health Canada) and Jee Young Kim (U.S. EPA) for Session Two; Mary Ross (U.S. EPA) and Thomas F. Bateson (U.S. EPA) for Session Three; and Terry Gordon (New York University) and James Brown (U.S. EPA) for Session Four. We would also like to thank Dr. Dana Barr, the Journal's editor, for her guidance throughout the completion of this special issue and the various peer reviewers for their insightful comments.

JEE YOUNG KIM ${ }^{\mathrm{a}}$, LESTER D. GRANT ${ }^{\mathrm{b}}$ AND RICHARD T. BURNETT

${ }^{a}$ U.S. EPA, National Center for Environmental AssessmentRTP Division, Research Triangle Park, North Carolina, USA

${ }^{\mathrm{b}}$ Retired from U.S. EPA

${ }^{\mathrm{c}}$ Health Canada, Safe Environments Directorate, Ottawa, Ontario, Canada E-mail:kim.jee-young@epa.gov 